\title{
SHEAR BEHAVIOUR OF STEEL FIBRE REINFORCED SELF-CONSOLIDADTING CONCRETE BEAMS BASED ON THE MODIFIED COMPRESSION FIELD THEORY
}

\author{
Yining DING ${ }^{1)}$, Fasheng ZHANG ${ }^{1)}$, Torgal Fernando ${ }^{2)}$ and Yulin ZHANG ${ }^{3)}$ \\ ${ }^{1)}$ State Key Laboratory of Coastal and Offshore Engineering \\ Dalian University of Technology \\ 116024 Dalian, China \\ ${ }^{2)}$ Research Unit C-TAC (Sustainable Construction Branch) \\ 4800-058 Guimarãs, Portugal \\ ${ }^{3)}$ Centre of Mathematics, University of Minho \\ 4700-052, Portugal
}

Key words: Steel fibres, Self-consolidating concrete beam, Modified compression field theory, Shear capacity, Hybrid effect.

Abstract: A series of steel fibre reinforced self-consolidating concrete (SFRSCC) beams have been tested to investigate the influence of steel fibres and the combined effect of fibers and stirrups on the deflection and cracking, ultimate loads and failure pattern. The experiment indicates that the shear strength increases clearly with the increasing of fibre content. The combination of steel fibres and stirrups demonstrates a positive composite effect on the ultimate load, ductility and failure pattern of concrete beam. This study also examines the feasibility of applying the modified compression field theory (MCFT) for the suitable assessment of shear resistance in fibre and steel rebar reinforced self-consolidating concrete beams. For fibre reinforced concrete member, a theoretical method is proposed based on the MCFT. The proposed ultimate shear capacity model was verified by the comparison with different test results.

\section{INTRODUCTION}

Concrete has low tensile strength and fails in a brittle manner. If fibres are added to the classical components of concrete, the steel fibre reinforced concrete (SFRC) can show higher toughness under static loading, such as tension, bending and shear. Steel fibres in the concrete can also enhance the mechanical properties, ductility and energy absorbing capacity under seismic, impact and blast loading [1]. One of the most important functions of steel fibres in concrete is the ability to transfer stresses across the cracked section, providing to concrete a residual strength, which magnitude depends on the fibre, matrix and fibre-matrix properties. The application of fibre reinforced self-consolidating concrete (SFRSCC) is one of the major part of special SCC. To increase the efficiency of steel fibres in concrete matrix, SFRSCC combines the benefits of SCC in the fresh state and shows some improved performances in the hardened state of steel fibre reinforced concrete (SFRC), especially the bond property between the fibre and the concrete matrix [2]. The most efficient applications of SFRSCC are those where the fibres can replace the conventional reinforcement. Some examples are 
applications in industrial floors, support of tunnellings, beams [3-6]. Nonetheless, the structural use of SFRSCC in the concrete industry has not yet been fully achieved because a design procedure that considers the randomly distributed discrete fibre behaviour across cracks in a rational manner is very rare.

Previous studies of shear carried out for structural applications of fibre reinforced concrete include slender and deep beams, with or without transverse reinforcement [7-15]. These studies indicate that the addition of fibres can greatly improve the shear capacity of beams. Fibres can be used either to boost the shear capacity or to replace, in part, the vertical stirrups in conventional reinforced concrete structural members. Although numerous experimental and theoretical investigations on shear problems of various fibrous concrete beams have been made during the past three decades, few are concerned with SFRSCC beams. Test data available on the reinforcing effect of fibres in the self-consolidating concrete members failing in shear are rather limited [16-17]. Most design code methods in treating shear still rely on empirical formulas, although some recent approaches, such as the plasticity theory or the modified compression field theory (MCFT), can be regarded as rational in the sense that they are capable of providing physical significance [13, 18-19].

This study examines the feasibility of applying the MCFT for the rational assessment of shear resistance in steel fibre-reinforced self-consolidating concrete beams, while providing experimental data to support the theory proposed, as well as to extend the current experimental database. An experimental program was therefore conducted to study the shear behaviour of SFRSCC beams containing longitudinal bars and vertical stirrups. Moreover, the hybrid effect of steel fibres and stirrups on the mechanical behaviour of beams was also studied.

\section{PROPOSED METHODS BASED ON MCFT}

The MCFT [20] is a further development of the CFT (compression field theory) that accounts for the influence of the tensile stresses in the cracked concrete. It was developed by observing the response of a large number of reinforced concrete (RC) elements loaded in pure shear or shear combined with axial stress. The relationship of the MCFT can be used to predict the shear strength of a beam subjected to shear, moment and axial load. The simplified MCFT for calculating shear strength of RC elements was also proposed [21-22]. In these models, the cracked concrete is treated as a new material with its own stress-strain characteristics. It is interesting to note that the fibre reinforced concrete is more suitable than plain concrete for the application of MCFT, due to its flatter stress-strain relationship in the post-peak range in compression and in tension than that of plain concrete, the studies of shear problems reflecting this are absent. The contribution of fibres to the shear capacity of SFRC can be taken into account based on the MCFT.

Failure of the RC element may be governed not by average stresses, but rather by local stresses that occur at a crack [20,23]. In checking the conditions at a crack, the actual complex crack pattern is idealized as a series of parallel cracks, all occurring at angle $\theta$ to the longitudinal reinforcement and space a distance $S_{\theta}$ apart. For a free-body diagram of part of fibre reinforced concrete element, Fig. 1 compares the calculated average stresses (Plane 1 in 
Fig. 1a) with the actual local stresses that occur at a crack (Plane 2 in Fig.1b). The critical crack direction is assumed normal to the principal tensile strain direction. While the calculated average shear stress on Plane 1 is zero, there may be local shear stresses on Plane 2.

As the applied external stresses are fixed, the two sets of stresses shown in Fig.1a and Fig.1b must be statically equivalent. Assuming a unit area for both Plane 1 and Plane 2, the requirement that the two sets of stresses produce the same force in the $\mathrm{z}$-direction is

$$
\rho_{s z} f_{s z} \cos \theta+f_{1} \cos \theta=\rho_{s z} f_{s z c r} \cos \theta-f_{c i} \cos \theta+v_{c i} \sin \theta+v_{f} \sin \theta+\sigma_{f} \cos \theta
$$

At high loads, the average strain in the stirrups $\varepsilon_{z}$ will typically exceed the yield strain of transverse steel. In this situation, both $f_{s z}$ and $f_{s z c r}$ will equal the yield stress in the stirrups, and then we can get Eqn. (2):

$$
f_{1}=\left(v_{c i}+v_{f}\right) \tan \theta+\sigma_{f}
$$

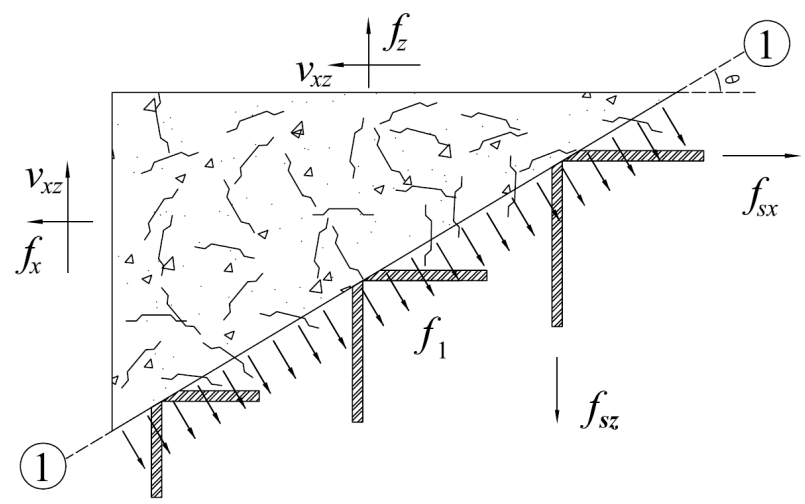

(a) Calculated Average Stresses

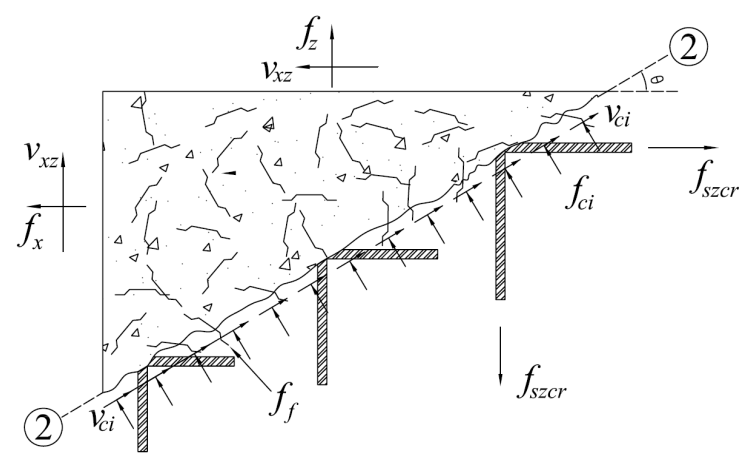

(b) Local Stresses at a Crack 


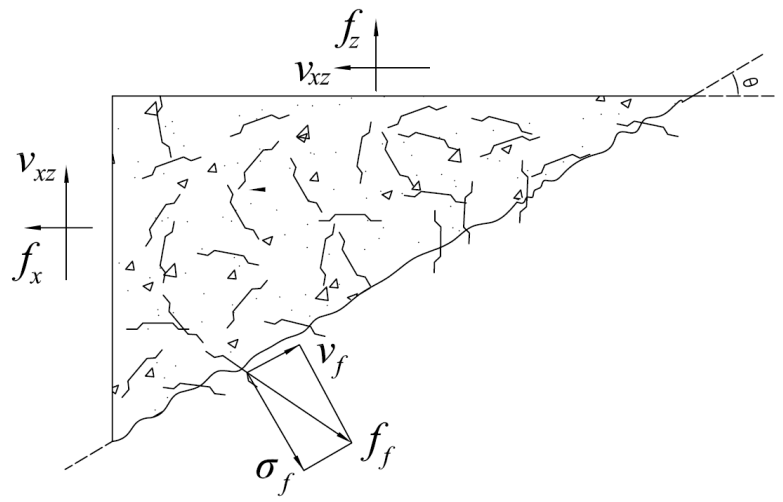

(c) Stress component of a single fibre transferred perpendicular to crack and parallel to crack

Fig.1 Comparison of local stresses at a crack with calculated average stresses of SFRC and stress state of a single fibre

A simplified concept for anisotropic contributions by hooked or paddled fibres to post-peak strength has been suggested by Stroeven P. in Eqn. (3) as follows [24-25]

$$
\sigma_{f}=v_{f}=\alpha \tau_{f} V_{f}(1+f)\left(1+\omega_{2} / 2\right)\left(1-4 w / l_{f}\right) / 3
$$

Where

$\alpha=$ the aspect ratio $\left(\alpha=l_{f} / d_{f} . l_{f}, d_{f}\right.$ are the length and diameter of fibres, respectively);

$\mathrm{T}_{f}=$ the average fibre matrix interfacial bond stress;

$\mathrm{V}_{f}=$ the volume fraction of fibres;

$\omega_{2}=$ the degree of planar orientation;

$w=$ the average crack width;

$f=$ the coefficient of friction between concrete and fibre sheared over the crack edge;

In the MCFT [20], equilibrium, compatibility and constitutive relationships are formulated in terms of average stresses and average strains. Relevant equations used in the MCFT for SFRC are summarized in Table 1.

Table 1 Equations of modified compression field theory for fibre reinforced concrete

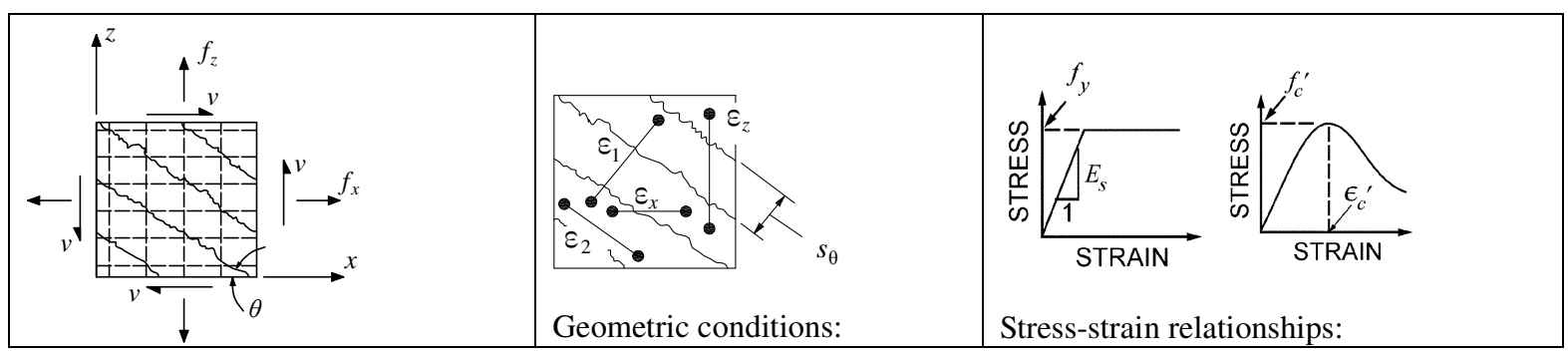




\begin{tabular}{|c|c|c|}
\hline $\begin{array}{l}\text { Equilibrium: } \\
\text { Average stresses: } \\
\begin{array}{ll}f_{x}=\rho_{x} f_{s x}+f_{1}-v \cot \theta \\
f_{z}=\rho_{z} f_{s z}+f_{1}-v \tan \theta \\
v=\left(f_{1}+f_{2}\right) /(\tan \theta+\cot \theta)\end{array}\end{array}$ & $\begin{array}{l}\text { Average strains: } \\
\tan ^{2} \theta=\frac{\varepsilon_{x}+\varepsilon_{2}}{\varepsilon_{z}+\varepsilon_{2}} \\
\varepsilon_{1}=\varepsilon_{x}+\varepsilon_{z}+\varepsilon_{2} \\
\gamma_{x z}=2\left(\varepsilon_{x}+\varepsilon_{2}\right) \cot \theta \\
\text { Crack widths: } \\
w=\varepsilon_{1} s_{\theta} \\
s_{\theta}=1 /\left(\frac{\sin \theta}{s_{x}}+\frac{\cos \theta}{s_{z}}\right)\end{array}$ & $\begin{array}{l}\text { Reinforcement: } \\
f_{s x}=E_{s} \varepsilon_{x} \leq f_{y x} \\
f_{s z}=E_{s} \varepsilon_{z} \leq f_{y z} \\
\text { Concrete: } \\
f_{2}=\frac{f_{\mathrm{c}}^{\prime}}{0.8+170 \varepsilon_{1}}\left[\frac{2 \varepsilon_{2}}{\varepsilon_{0}}-\left(\frac{\varepsilon_{2}}{\varepsilon_{0}}\right)^{2}\right] \\
f_{1}=\frac{0.33 \sqrt{f_{c}^{\prime}}}{1+\sqrt{500 \varepsilon_{1}}}+\sigma_{f} \\
\text { Shear stress on crack: } \\
v_{c i} \leq \frac{0.18 \sqrt{f_{\mathrm{c}}^{\prime}}}{0.31+\frac{24 w}{d_{\mathrm{a}}+16}}+v_{f}\end{array}$ \\
\hline \multicolumn{3}{|c|}{$\begin{array}{l}\text { Where } \rho_{x} \text { and } \rho_{z}=\text { the reinforcement ratios in the longitudinal and transverse direction; } f_{\mathrm{c}}^{\prime}=\text { cylinder compressive } \\
\text { strength; } d_{a}=\text { maximum aggregate size; } f_{s x}, f_{\mathrm{sz}}=\text { average stresses in the longitudinal and transverse reinforcement; } \\
f_{1}=\text { average tensile stress; } f_{2}=\text { average compressive stress; } \theta=\text { inclination of the diagonal compressive; } v=\text { shear } \\
\text { strength; } \varepsilon_{x}=\text { average longitudinal strain; } ; \varepsilon_{y}=\text { average transverse strain; } ; \varepsilon_{2}=\text { principal compressive strain; } \varepsilon_{1}= \\
\text { principal tensile strain; } v_{c i}=\text { shear stress on the crack face; } w=\text { average crack width; } S_{\theta}=\text { average crack spacing; } S_{x} \text {, } \\
S_{z}=\text { indicators of the crack control characteristics of the } x \text {-reinforcement and the } z \text {-reinforcement. }\end{array}$} \\
\hline
\end{tabular}

The relationships mentioned in Table 1 of the proposed theory can be used to predict the shear strength of a SFRSCC beam. Assuming that the shear stress in the web is equal to the shear force divided by the effective shear area $b_{w} d_{v}$, and that, at failure, the stirrups will yield, equilibrium Eqn. (5) can be rearranged to give the following expression for the shear strength $V_{n}$ of the section

$$
\begin{gathered}
V_{n}=V_{c}+V_{s} \\
V_{n}=f_{1} b_{w} d_{v} \cot \theta+A_{v} f_{y} d_{v} \cot \theta / s
\end{gathered}
$$

In this case for design, the fibre distribution is assumed to be three dimensional (spatial portions) [24-25].

$$
\sigma_{f}=\alpha \tau_{f} V_{f}(1+f) / 3
$$

Therefore, if we consider the fibre effect on the shear capacity, we can get Eqn. (22) and Eqn. (23) as follows:

$$
V_{n}=\left[v_{c i}+\alpha \tau_{f} V_{f}(1+f)(1+\cot \theta) / 3\right] b_{w} d_{v}+A_{v} f_{y} d_{v} \cot \theta / s
$$




$$
V_{n}=\left[\beta \sqrt{f_{c}^{\prime}}+\alpha \tau_{f} V_{f}(1+f)(1+\cot \theta) / 3\right] b_{w} d_{v}+A_{v} f_{y} d_{v} \cot \theta / s
$$

The proposed Eqn. (23) is a modified version of the 2004 CSA expression for calculating of the ultimate shear capacity of SFRC beams. The determination of $\beta$ and $\theta$ is based on the 2004 CSA general method [26-27].

\section{EXPERIMENTAL PROGRAM}

\subsection{Materials}

In this test program, the concrete mixture was made with ordinary Portland cement (CEM I 42.5), fly ash, natural sand ( $0-5 \mathrm{~mm})$, crushed gravel of $10 \mathrm{~mm}$ maximum size. To improve the workability, a ploycarboxylic acid-based high-range water-reducing admixture (HRWRA), was added after extensive trials. Table 2 summarizes the mixture proportions of SFRSCC employed in this testing program. The hooked-ended macro steel fibre RC-80/60-BN (fibre length $l_{f}=60 \mathrm{~mm}$, equivalent diameter $d_{f}=0.75 \mathrm{~mm}$, aspect ratio $l_{f} / d_{f}=$ 80 , ca. 15,000 pieces $/ \mathrm{kg}$, tensile strength $1100 \mathrm{~N} / \mathrm{mm}^{2}$ ) was used (Fig. 2). The fibre contents added into the mixture were $0,20 \mathrm{~kg} / \mathrm{m}^{3}, 40 \mathrm{~kg} / \mathrm{m}^{3}$ and $60 \mathrm{~kg} / \mathrm{m}^{3}$. The details of the deformed steel bars with a diameter of $16 \mathrm{~mm}$ as longitudinal reinforcement can be seen in the Fig. 3 . Hot-rolled plain bars with a diameter of $6.5 \mathrm{~mm}(\Phi 6.5)$ and a diameter of $8 \mathrm{~mm}(\Phi 8)$ were used as stirrups and the top longitudinal reinforcement respectively. The longitudinal reinforcement and stirrup had a yield stress of $430 \mathrm{MPa}$ and $300 \mathrm{MPa}$ with an ultimate stress of $650 \mathrm{MPa}$ and $500 \mathrm{MPa}$ respectively.

Table 2 Mix propottion

\begin{tabular}{lcccccc}
\hline $\begin{array}{l}\text { Cement } \\
/ \mathrm{kg} \cdot \mathrm{m}^{-3}\end{array}$ & $\begin{array}{c}\text { Fly ash } \\
/ \mathrm{kg} \cdot \mathrm{m}^{-3}\end{array}$ & $\begin{array}{c}\text { Water } \\
/ \mathrm{kg} \cdot \mathrm{m}^{-3}\end{array}$ & $\begin{array}{c}\text { Sand } \\
/ \mathrm{kg} \cdot \mathrm{m}^{-3}\end{array}$ & $\begin{array}{c}\text { Gravel } \\
/ \mathrm{kg} \cdot \mathrm{m}^{-3}\end{array}$ & $\begin{array}{c}\text { Super-plasticizer } \\
(\%)\end{array}$ & W/B \\
\hline 400 & 170 & 200 & 742 & 724 & 1.40 & 0.35 \\
\hline
\end{tabular}




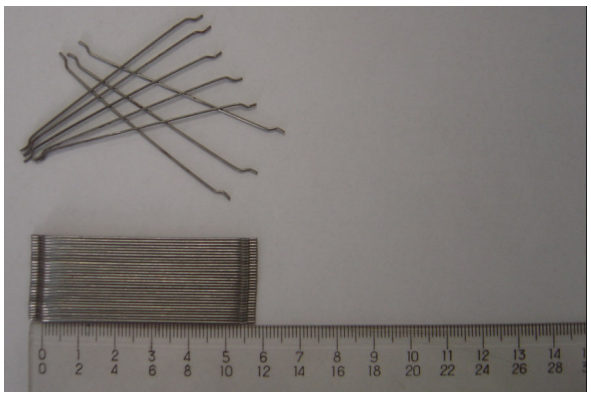

Fig. 2 Macro steel fibres

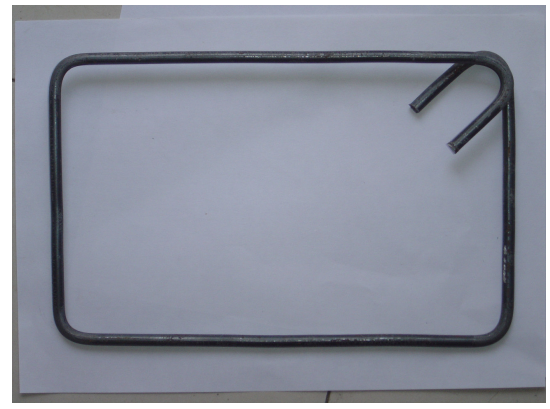

Fig. 3Stirrup

\subsection{Test specimens}

A series of steel fibre reinforced SCC beams were tested. All beams with a dimension of B (width) $\times \mathrm{H}$ (depth) $\mathrm{L} \mathrm{L}$ (length) $=100 \mathrm{~mm} \times 150 \mathrm{~mm} \times 1400 \mathrm{~mm}$, were tested on a span of $l_{s}$ $=1140 \mathrm{~mm}$. The beams had three different stirrup ratios $\left(\rho_{v}\right)$ and three different fibre contents. The longitudinal reinforcement ratio $\left(\rho_{s}=3.35 \%\right)$ and the shear span-to-depth ratio $(a / d=4)$, were kept constant. More details of the test specimens are illustrated in Table 3. Longitudinal tensile reinforcement has 90-degree hooks at the beam ends to ensure adequate anchorage, and additional stirrups were provided at the concentrated loading point of midspan and support for preventing of the local failure. The specimen dimension and reinforcement layout are shown in Fig. 4.

Table 3 Details of test beams

\begin{tabular}{lccccc}
\hline Beam No. & $\begin{array}{c}\text { Dimension } \\
/ \mathrm{mm}\end{array}$ & $a / d$ & $\begin{array}{c}\text { Stirrup ratio } \\
/ \%\end{array}$ & $\begin{array}{c}\text { Stirrup spacing } \\
/ \mathrm{mm}\end{array}$ & $\begin{array}{c}\text { Fibre content } \\
/ \mathrm{kg} \cdot \mathrm{m}^{-3}\end{array}$ \\
\hline SSF0- $\infty$ & & 4 & 0 & $\infty$ & 0 \\
SF20- $\infty$ & 4 & 0 & $\infty$ & 20 \\
SF40- $\infty$ & 4 & 0 & $\infty$ & 40 \\
SF60- $\infty$ & 4 & 0 & $\infty$ & 60 \\
SF0-480 & & 4 & 0.138 & 480 & 0 \\
SF20-480 & & 0.138 & 480 & 20 \\
SF40-480 & & 0.138 & 480 & 40 \\
SF60-480 & $b=100$ & 4 & 0.138 & 480 & 60 \\
SF0-240 & $h=150$ & 4 & 0.275 & 240 & 0 \\
SF20-240 & $l_{S}=1140$ & 4 & 0.275 & 240 & 20 \\
SF40-240 & & 4 & 0.275 & 240 & 40 \\
SF60-240 & & 4 & 0.275 & 240 & 60 \\
SF0-160 & 4 & 0.413 & 160 & 0 \\
SF20-160 & 4 & 0.413 & 160 & 20 \\
SF40-160 & & 4 & 0.413 & 160 & 40 \\
SF60-160 & & 4 & 0.413 & 160 & 60 \\
\hline
\end{tabular}




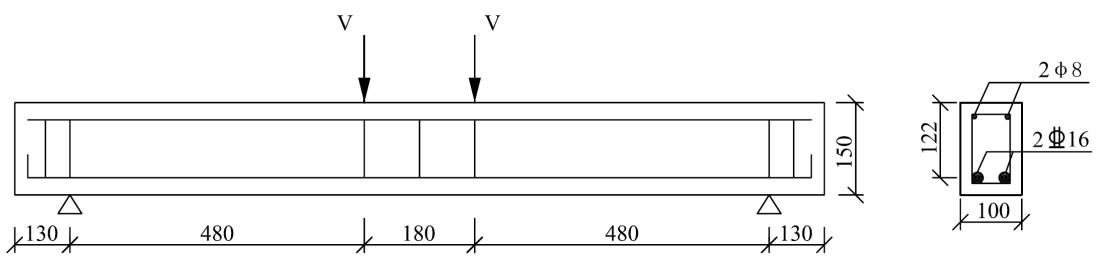

(a) Reinforcement detail of SF- $\infty$

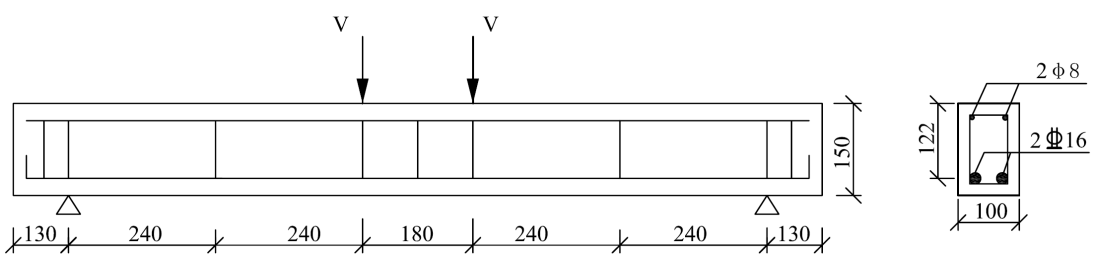

(b) Reinforcement detail of SF-480

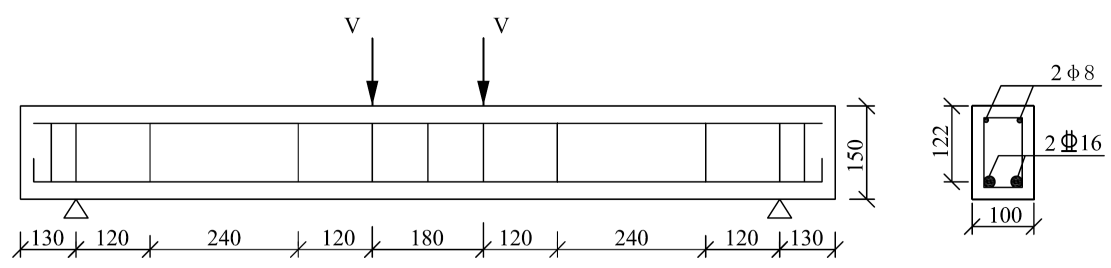

(c) Reinforcement detail of SF-240

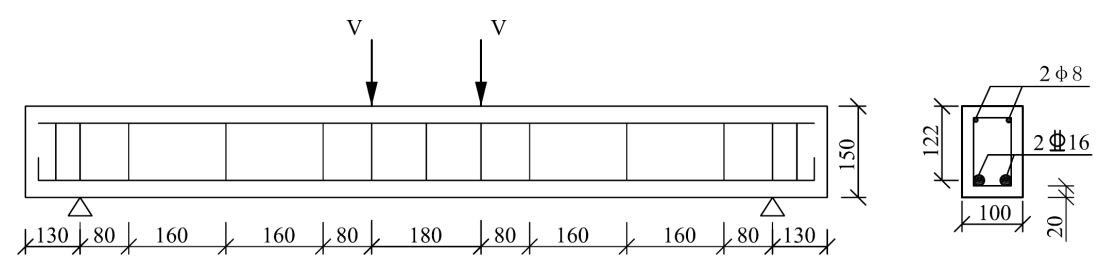

(d) Reinforcement detail of SF-160

Fig. 4 Dimension and reinforcement details of test beams (units: $\mathrm{mm}$ ) 


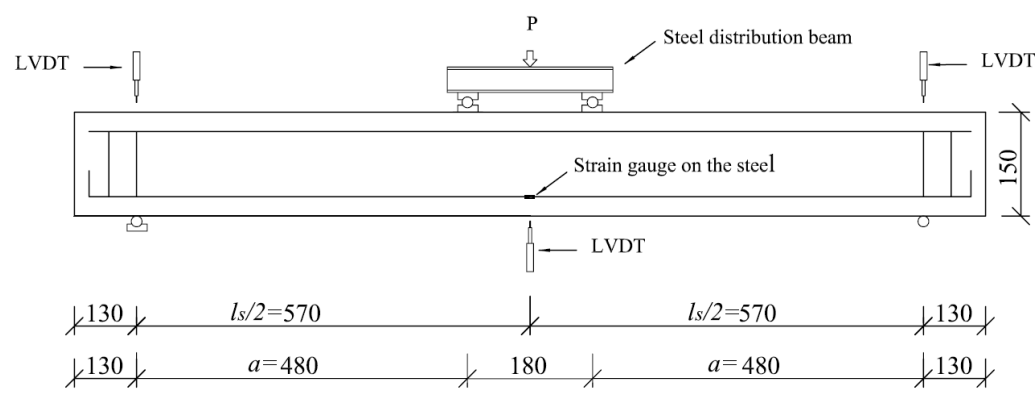

Fig. 5 Loading and measuring arrangement of test beams (units: mm)

\subsection{Testing procedures}

\subsubsection{Properties of fresh and hardened concrete}

The workability of fresh SCC was evaluated according to the reference [28-29]. The test methods used in this research included slump flow test (for assessing the workability and filling ability), L-box test (for assessing passing ability and flowability). They were sufficient to monitor production quality. In order to simulate the reinforcement ratio of the beam, the steel ratio of the L-box was equal to that of $\mathrm{RC}$ beam $\left(\rho_{s}=3.35 \%\right)$.

The 28-day concrete compressive strength was measured using 150x150x150 mm cubic specimen following the Chinese guideline [30].

\subsubsection{Experimental beam test setup}

Monotonic loading was provided with a $10000 \mathrm{kN}$ hydraulic servo testing machine using a steel distribution beam with special bearing assemblies on the top face of the beam. The tests for load - displacement responses were deformation-controlled and the deformation rate of test was $0.2 \mathrm{~mm} / \mathrm{min}$ [31]. The vertical deflection at the mid-span was monitored and recorded by a linear voltage differential transformer (LVDT) installed around the test beam. Electrical-resistance strain gages were used to record the strains in the concrete as well as reinforcement at several selected locations, as shown in Fig.5.

\section{EXPERIMENTAL RESULTS}

\subsection{Workability and compressive strength}

The experimental results of workability of steel fibre reinforced fresh SCC are presented in Table 4 . The factor $d_{m}$ represents the average final diameter, while factor $T_{500}$ represents the time taken for the mixture to reach the $500 \mathrm{~mm}$ spread circle in slump flow test. Parameters $T_{200}$ and $T_{400}$ represent the time taken for the mixture to reach $200 \mathrm{~mm}$ and $400 \mathrm{~mm}$ in the L-box. The ratio $H_{2} / H_{1}$ represents the blocking in the in the L-box. It can be seen from Table 4 that all parameters regarding workability meet the requirements of SCC according to 
EFNARC [28]. When steel fibre content is $60 \mathrm{~kg} / \mathrm{m}^{3}$, the value of $H_{2} / H_{1}$ is low which just fulfilled the requirements. It means that the steel fibre content of $60 \mathrm{~kg} / \mathrm{m}^{3}$ could achieve the upper limit of the workability of SFRSCC, when the steel ratio $\left(\rho_{s}\right)$ of RC beam arrives $3.35 \%$. The typical slump flow test and L-box test for SFRSCC mixture is depicted in Fig. 6.

The cubic compressive strength $f_{c u}$ and equivalent cylinder compressive strength $f^{\prime}{ }_{c}$ of steel fibre reinforced SCC at 28 days are also listed in Table 4. The addition of fibres aids in converting the brittle properties of concrete into a ductile material, however no significant trend of improving compressive strength was observed.

Table 4 Fresh and mechanical properties of SFRSCC mixture

\begin{tabular}{|c|c|c|c|c|c|c|c|}
\hline \multirow[b]{2}{*}{$\begin{array}{l}\text { Fibre contents } \\
/ \mathrm{kg} \cdot \mathrm{m}^{-3}\end{array}$} & \multicolumn{2}{|c|}{ Slump flow } & \multicolumn{3}{|c|}{ L-box } & \multirow[b]{2}{*}{$f_{c u, 28} / \mathrm{MPa}$} & \multirow[b]{2}{*}{$f_{c, 28}^{\prime} / \mathrm{MPa}$} \\
\hline & $\begin{array}{r}d_{m} \\
/ \mathrm{mm}\end{array}$ & $\begin{array}{c}T_{500} \\
/ \mathrm{s}\end{array}$ & $H_{2} / H_{1}$ & $\begin{array}{c}T_{200} \\
/ \mathrm{s}\end{array}$ & $\begin{array}{c}T_{400} \\
/ \mathrm{s}\end{array}$ & & \\
\hline 0 & 780 & 4.2 & 0.89 & 2.2 & 5.1 & 39.3 & 33.8 \\
\hline 20 & 760 & 4.0 & 0.85 & 2.8 & 5.5 & 41.9 & 36.0 \\
\hline 40 & 740 & 3.8 & 0.83 & 3.0 & 5.8 & 37.8 & 32.5 \\
\hline 60 & 700 & 3.7 & 0.78 & 5.0 & 10.0 & 47.9 & 41.2 \\
\hline
\end{tabular}

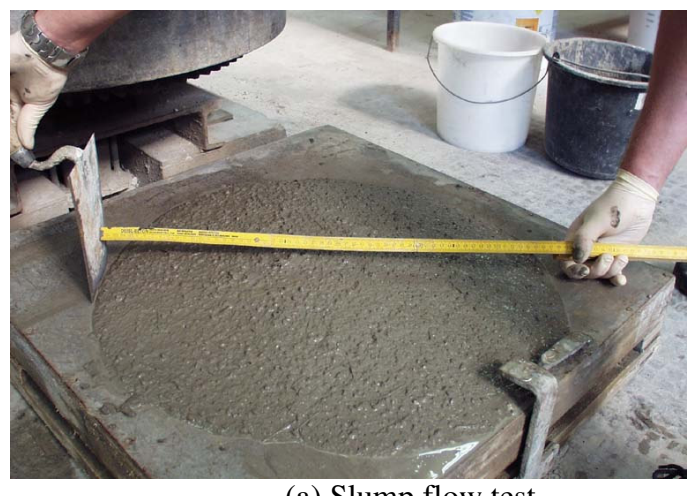

(a) Slump flow test

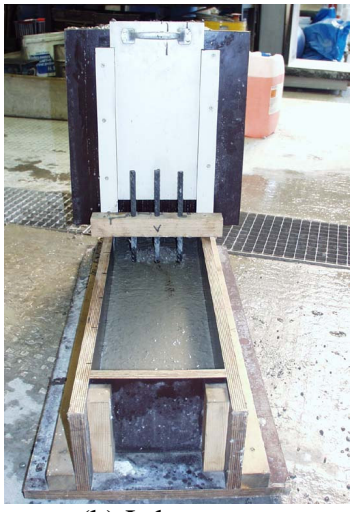

(b) L-box test

Fig. 6 Tests of workability of SCC with $60 \mathrm{~kg} / \mathrm{m}^{3}$ fibres

\subsection{Load-deflection behaviour}

Fig. 7 presents the effect of fibre addition on the load-midspan deflection for the SFRSCC 
beams. The addition of steel fibres may enhance the cracking load and ultimate load of SCC beams.

Shear failure occurred in all beams without stirrups (Fig. 7a). The beam SF0- $\infty$ showed both lower ultimate load carrying capacity $\left(F_{u}=40.7 \mathrm{kN}\right)$ and brittle failure pattern. After the ultimate load $F_{u}$, the beam SF0- $\infty$ showed low post-peak behaviour and the load carrying capacity declined abruptly. Compared to the beam SF0- $\infty, F_{u}$ of a beam with $20 \mathrm{~kg} / \mathrm{m}^{3}$ steel fibres (SF20- $\infty$ ) increased about $17.8 \%$. It can be observed that the beam without fibres failed soon after the first diagonal crack appeared. However, the addition of steel fibres can change the brittle failure pattern of a beam into a more ductile one. More closely spaced cracks were observed in fibre reinforced beams than those without fibres. The crack spacing and crack width under the same load clearly declined with the increasing of fibre content (Fig. 8). The steel fibres became effective after cracking, with a more evenly stress redistribution over the cracking region, and continued to resist the tensile stresses until the pullout of the fibres.

In comparison with beam SF0-480, the addition of $20 \mathrm{~kg} / \mathrm{m}^{3}$ and $40 \mathrm{~kg} / \mathrm{m}^{3}$ steel fibres can enhance the ultimate load $F_{u}$ by about $33 \%$ and $61.5 \%$ respectively. However, the beams with only $20 \mathrm{~kg} / \mathrm{m}^{3}$ and $40 \mathrm{~kg} / \mathrm{m}^{3}$ steel fibre still exhibited some brittle diagonal failure patterns. After $F_{u}$, the load carrying capacity decreased clearly (Fig. 7b). The addition of $60 \mathrm{~kg} / \mathrm{m}^{3}$ steel fibres can transform the brittle shear failure pattern of SF0-480 into a well ductile flexure failure pattern of SF60-480. This means that the addition of $60 \mathrm{~kg} / \mathrm{m}^{3}$ steel fibres had a strong effect on the failure pattern and deformability of conventional steel rebar reinforced beam. It also indicated high composite effect efficiency between steel fibres and stirrups. The beams with a stirrup spacing of $240 \mathrm{~mm}$ and $160 \mathrm{~mm}$ (Fig. 7 (c) and (d)) followed the same trend.

Generally, for each stirrup ratio ( $\rho_{v}=0$ in Fig.7(a), $0.138 \%$ in Fig.7(b), $0.275 \%$ in Fig.7(c) and $0.413 \%$ in Fig.7(d)), following three points can be observed:

- The post-peak behaviour and the ductility of concrete beams increased clear with the increasing of fibre dosage.

- The failure pattern of SCC beams is transformed gradually from the brittle shear failure into a ductile flexure failure with the increasing of fibre dosage.

- The well distributed fibres in beam acting as a three dimensional net [4-6] can also transfer the tensile force, hence, the post crack behaviour of steel fibre reinforced RC beams show a great improvement compared to those of SCC without fibres or only with stirrups. 


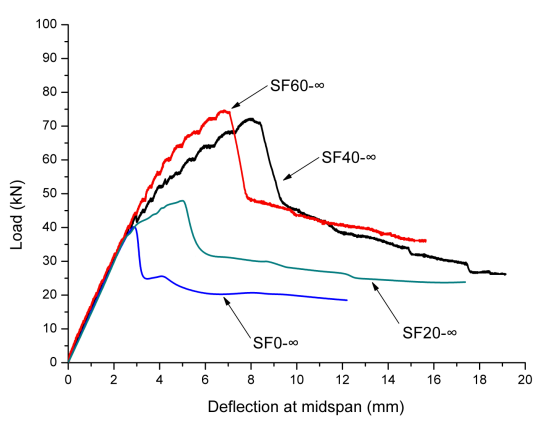

(a) SF- $\infty$

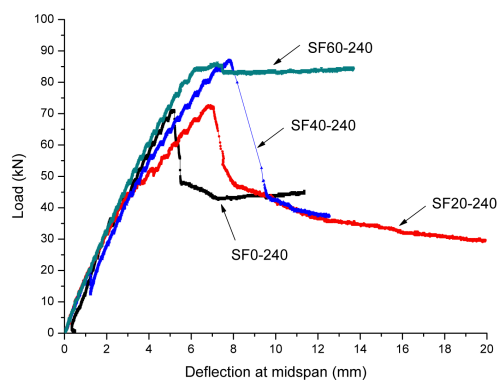

(c) SF-240

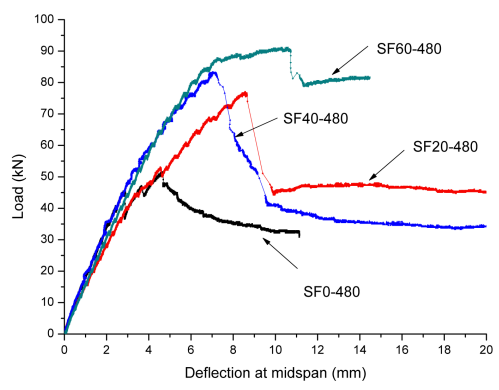

(b) SF-480

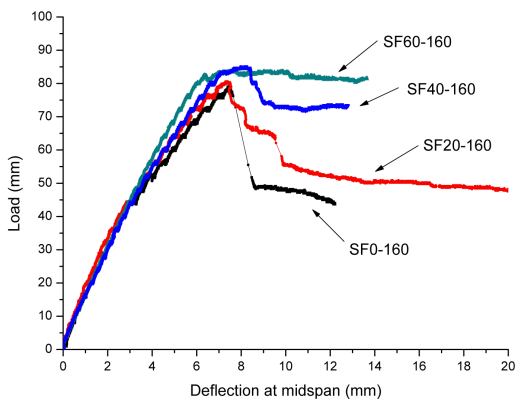

(d) SF-160

Fig. 7 Load-deflection responses with different stirrup ratios

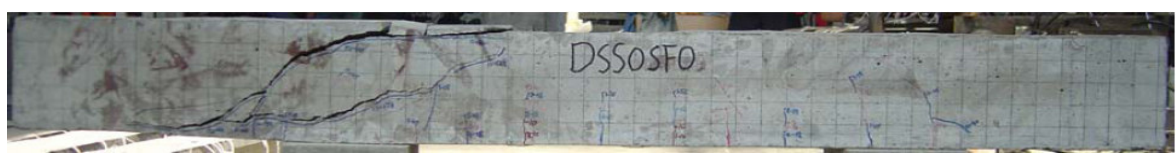

(a) $\mathrm{SF} 0-\infty$

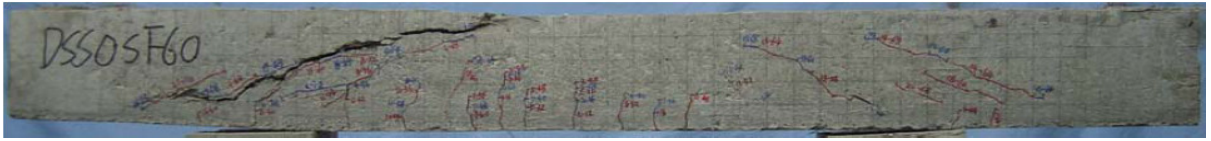

(b) SF60- $\infty$

Fig. 8 Cracks and failure patterns of beams witout stirrups 


\subsection{Toughness}

In this study, the post-peak behaviour of test beams in terms of flexural toughness parameters was evaluated. According to the reference [5], two toughness parameters $\left(\mathrm{D}^{\mathrm{f}}{ }_{8}\right.$, $\mathrm{f}_{\text {eq.8 } 8}^{\mathrm{f}}$ ) were introduced to evaluate the energy absorption capacity and the residual load bearing capacity of the test beams to a deflection $\delta_{8}=\delta_{\mathrm{cr}}+8 \mathrm{~mm}$. $\mathrm{D}_{8}$ can be defined as the area under load-deflection curve, which is the total energy absorbed up to the certain deflection $\delta_{8}$ of the beam. The equivalent strength $\mathrm{f}_{\text {eq. } 8}^{\mathrm{f}}$ can be determined by means of the following expressions:

$$
f_{\text {eq. } 8}^{f}=D_{8}^{f} l_{s} / 6 b_{w} d_{v}^{2}
$$

The calculated results of energy absorption and equivalent strengths of test beams with different stirrup ratios are presented in Table 5. It can be seen that the beam only with stirrups (SF0-480, SF0-240) showed relatively low toughness. The combined using of stirrups and steel fibres demonstrated a positive hybrid effect in improving the post-peak behaviour as well as toughness of test beams (see Fig. 7 and Fig. 9).

Fig. 9 presents the hybrid effect of stirrups $\left(\rho_{v}=0.138 \%, 0.275 \%\right)$ and steel fibres on toughness parameter $\left(\mathrm{f}_{\text {eq. }}^{\mathrm{f}}\right)$. It can be seen that a steel fibre content of $20 \mathrm{~kg} / \mathrm{m}^{3}$ can replace at least a stirrup ratio of $0.137 \%$. It means that the addition of $20 \mathrm{~kg} / \mathrm{m}^{3}$ steel fibres can enlarge the stirrup spacing from $240 \mathrm{~mm}$ to $480 \mathrm{~mm}$. The combined use of stirrups and steel fibres demonstrates strong positive hybrid effect on shear load-carrying capacity, the post-crack behaviour and toughness of SCC beams subjected to shear and bending.

Table 5 Comparison of energy absorption and equivalent flexural strength

\begin{tabular}{lcc}
\hline Beam No. & $\begin{array}{c}D_{8}^{f} \\
/(\mathrm{kN} . \mathrm{mm})\end{array}$ & $\begin{array}{c}f_{\text {eq.8 }}^{f} \\
/\left(\mathrm{N} / \mathrm{mm}^{2}\right)\end{array}$ \\
\hline SF0- $\infty$ & 190.35 & 24.30 \\
SF20- $\infty$ & 287.81 & 36.74 \\
SF40- $\infty$ & 367.74 & 46.94 \\
SF60- $\infty$ & 385.02 & 49.15 \\
SF0-480 & 284.42 & 36.31 \\
SF20-480 & 354.08 & 45.20 \\
SF40-480 & 425.65 & 54.34 \\
SF60-480 & 426.49 & 54.44 \\
SF0-240 & 325.83 & 41.59 \\
SF20-240 & 363.06 & 46.35 \\
SF40-240 & 412.98 & 52.72 \\
SF60-240 & 440.69 & 56.26 \\
SF0-160 & 386 & 49.27 \\
SF20-160 & 406.69 & 51.92 \\
SF40-160 & 425.95 & 54.25 \\
SF60-160 & 438.6 & 55.99 \\
\hline
\end{tabular}




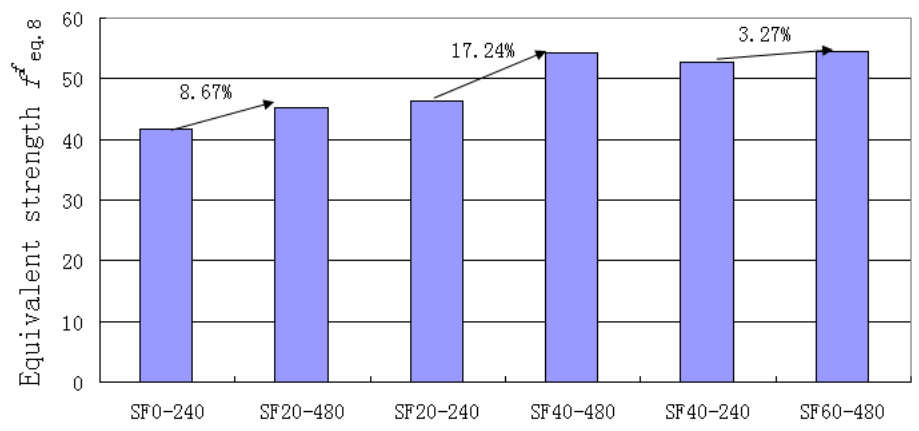

Fig. 9 Increase ratio of the toughness parameter for beams with different reinforcements

The positive hybrid effect of stirrups and steel fibres on the concrete member can demonstrate some advantages as follows:

- Enhancing of the residual load-bearing capacity in the post-peak zone greatly

- Changing the failure pattern from a brittle diagonal shear failure into a ductile bending failure pattern with the increasing of fibre dosage

- Replacing of the stirrups of RC members, only $20 \mathrm{~kg} / \mathrm{m}^{3}$ steel fibres can replace partially stirrups and enlarge the stirrup spacing from 240 to $480 \mathrm{~mm}$.

Besides, the combined application of stirrups and steel fibres in concrete beam can also 1 )

reduce the construction period and the cost of assembling reinforcement, 2 )affect the concrete casting and 3) improve the concrete quality and 4) increase the bond behaviour between the steel rebar and concrete matrix.

Steel fibres, which are well distributed three-dimensionally in the beam, can orientate parallel to the trajectory of the principle tensile stress, they are efficient to resist the diagonal shear force and work partly as shear reinforcement. Therefore, the joint action of fibres and stirrups are more effective in arresting diagonal crack propagation than that of mono reinforcement and can greatly increase the shear capacity and ductility.

\subsection{Shear cracking load and ultimate load}

The shear cracking load $F_{c r}$ (diagonal cracking load), the ultimate load $F_{u}$ and the failure mode are summarized in Table 6 . A careful examination of these results indicates that both $F_{c r}$ and $F_{u}\left(=2 V_{u}\right.$, exp $)$ of SFRSCC beams are influenced by the fibre content and the stirrup ratio. Table 6 shows that the effect of fibre content on $F_{c r}$ and $F_{u}$ of the test beams with different stirrup ratios. Form Table 6 it can be seen that the shear cracking load $F_{c r}$ increases with the increasing of the fibre content and the increase rate is low as $\rho_{v}$ becomes bigger. The maximum increase rate in $F_{c r}$ was about $200 \%$ for beam SF60- $\infty$. The maximum increase in $F_{u}$ was about $82.3 \%$ for the beam SF60- $\infty$. With the increase of stirrup ratio, the beams failed in flexure and the applied load at failure was determined by the yield of longitudinal reinforcement or crush of concrete. Therefore, the ultimate load did not increase clearly with 
the increasing of fibre content at high stirrup ratios.

Table 6 Comparisons between predicted and observed loads

\begin{tabular}{|c|c|c|c|c|c|c|}
\hline Beam no. & $F_{c r} / \mathrm{kN}$ & $F_{u} / \mathrm{kN}$ & $\begin{array}{c}V_{u, \exp } \\
/ \mathrm{kN}\end{array}$ & $\begin{array}{l}V_{u, \text { pre }} \\
/ \mathrm{kN}\end{array}$ & $\begin{array}{l}\text { failure } \\
\text { Pattern }\end{array}$ & $V_{u, \exp } / V_{u, p r e}$ \\
\hline SF0- $\infty$ & 10 & 40.7 & 20.35 & - & shear & - \\
\hline SF20- $\infty$ & 15 & 48.00 & 24.00 & 19.07 & shear & 1.259 \\
\hline SF $40-\infty$ & 19.6 & 72.22 & 36.11 & 26.51 & shear & 1.362 \\
\hline SF60- $\infty$ & 30.2 & 74.65 & 37.33 & 36.32 & shear & 1.028 \\
\hline SF0-480 & 10.6 & 51.53 & 25.77 & - & shear & - \\
\hline SF20-480 & 16.1 & 77.07 & 38.54 & 26.09 & shear & 1.477 \\
\hline SF40-480 & 20.5 & 83.23 & 41.62 & 33.53 & shear & 1.241 \\
\hline SF60-480 & 20.8 & 91.16 & 45.58 & 43.34 & flexure & 1.052 \\
\hline SF0-240 & 12.1 & 68.04 & 34.02 & - & shear & - \\
\hline SF20-240 & 14.2 & 72.66 & 36.33 & 33.10 & shear & 1.098 \\
\hline SF40-240 & 15.2 & 86.98 & 43.49 & 40.55 & shear & 1.072 \\
\hline SF60-240 & 16.1 & 86.32 & 43.16 & 50.36 & flexure & 0.857 \\
\hline SF0-160 & 15 & 79.27 & 39.64 & - & shear & - \\
\hline SF20-160 & 17 & 80.59 & 40.30 & 40.12 & shear & 1.005 \\
\hline SF40-160 & 21 & 84.56 & 42.28 & 47.56 & flexure & 0.889 \\
\hline \multirow[t]{2}{*}{ SF60-160 } & 21.3 & 84.12 & 42.06 & 57.37 & flexure & 0.733 \\
\hline & & & & & & $\begin{array}{c}\text { Mean }=1.089 \\
C V=0.198\end{array}$ \\
\hline
\end{tabular}




\subsection{Prediction and comparison}

In addition to the tensile capacity of the fibres, the traditional CSA expression is modified to account for the improvement in dowel action imparted by the fibres and the enhancement of the interlocking of aggregates. Based on the regression analysis, the Eqn. (23) is modified to the following proposed equations:

For SFRSCC beams:

$$
V_{n}=\left[\beta \sqrt{f_{c}^{\prime}}+\alpha \tau_{f} V_{f}(1+f)(1+\cot \theta) / 3\right] b_{w} d_{v}+A_{v} f_{y} d_{v} \cot \theta / s
$$

For SFRC beams:

$$
V_{n}=4 d / a\left[\beta \sqrt{f_{c}^{\prime}}+\alpha \tau_{f} V_{f}(1+f)(1+\cot \theta) / 3\right] b_{w} d_{v}+A_{v} f_{y} d_{v} \cot \theta / s
$$

The ultimate load prediction of test beams was made using the proposed methods for shear and compared with the corresponding measured failure load $\left(\mathrm{V}_{\mathrm{u}, \exp }\right)$ in Table 6 .

To extend the validity of the proposed method for the shear strength, the prediction was made for beams that had been tested in previous studies. For FRSCC, the investigation was limited to slender beams $(a / d \geq 3)$ due to the lack of experimental data. The dimensions and properties are summarized in Table 7. A comparison of the experimental-to-predicted shear capacity data for the modified CSA expression is also presented in Fig. 10 along with the associated coefficient of determination $\left(R^{2}\right)$, mean absolute error (MAE), and the average measured -to-predicted shear capacity ratio $\left(\mathrm{V}_{\mathrm{m}} / \mathrm{V}_{\mathrm{p}}\right)$.

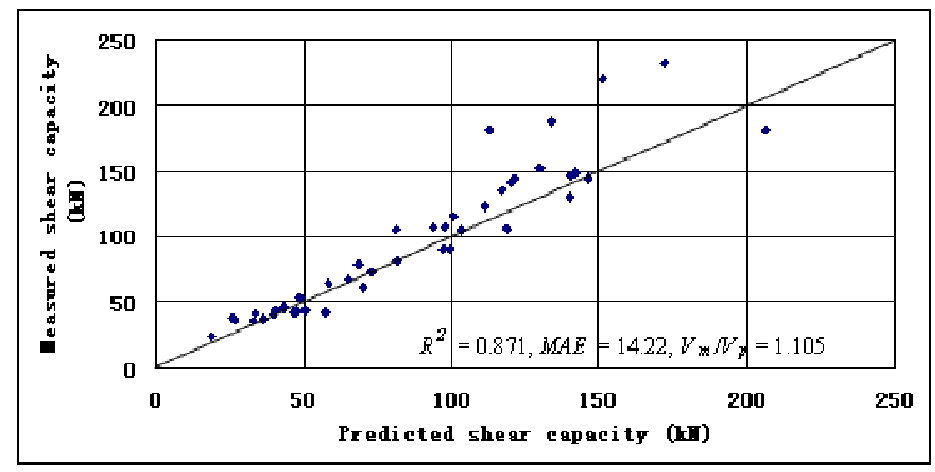

Fig. 10 Measured shear capacity versus predicted values by modified CSA equation

By comparing measured and predicted ultimate loads in Table 7 and Fig. 10, it can be seen that the solutions based on the proposed method correlate well with the experimental results of fibre reinforced SCC beams without stirrups, having a mean of 1.07 and a CV (coefficient of variation) of 0.095 . However, the proposed method provides a conservative prediction for 
the shear capacity of fibre reinforced SCC beams with stirrups, having a mean of 1.380 and a $\mathrm{CV}$ of 0.098 . This may be attributed to the influence of the longitudinal reinforcing steel and stirrups on the shear capacity of fibre reinforced RC beams, which becoming more pronounced with the addition of fibres. Despite its better fit, the modified CSA equation is not conservative for any of the three data sets (Ashour et al, Kwak, Tom Greenough), but with the incorporation of a reduction factor it could provide a reliable and conservative prediction of the shear capacity for beams without stirrups.

Table 7 Summary of beam details and comparison of experimental and predicted shear strengths

\begin{tabular}{|c|c|c|c|c|c|c|c|c|c|c|c|c|c|c|c|c|c|}
\hline Investigator & Beam no. & $\begin{array}{l}\text { Fibre } \\
\text { type }\end{array}$ & $V_{f}(\%)$ & $l y d_{f}$ & $f_{c}^{\prime}$ & $b_{w}$ & $d_{v}$ & ald & $\rho_{s}(\%)$ & $f_{y s}$ & $d_{a}$ & $\rho_{v}(\%)$ & $f_{y v}$ & $s$ & $V_{\text {uepp }}$ & $V_{\text {Lprodiaced }}$ & $V_{\text {uexp }} / V_{\text {uppratiaed }}$ \\
\hline \multirow{7}{*}{$\begin{array}{c}\text { Ashour et al } \\
{[9]}\end{array}$} & B-2-0.5-A & \multirow{6}{*}{ Hooked } & 0.5 & 75 & 99.1 & 125 & 215 & 2.0 & 2.84 & 460 & 10 & & & & 129.54 & 140.2 & 0.924 \\
\hline & B-4-0.5-A & & 0.5 & 75 & 95.4 & 125 & 215 & 4.0 & 2.84 & 460 & 10 & & & & 61.01 & 70.1 & 0.870 \\
\hline & B-6-0.5-A & & 0.5 & 75 & 95.83 & 125 & 215 & 6.0 & 2.84 & 460 & 10 & & & & 42.73 & 46.73 & 0.915 \\
\hline & B-2-1.0-M & & 1.0 & 75 & 94.5 & 125 & 215 & 2.0 & 4.58 & 470 & 10 & & & & 180.87 & 206.24 & 0.873 \\
\hline & B-41.0-M & & 1.0 & 75 & 93.8 & 125 & 215 & 4.0 & 4.58 & 470 & 10 & & & & 104.28 & 103.12 & 1.011 \\
\hline & B-6-1.0-M & & 1.0 & 75 & 95.0 & 125 & 215 & 6.0 & 4.58 & 470 & 10 & & & & 78.74 & 68.75 & 1.146 \\
\hline & & & & & & & & & & & & & & & & & $\begin{array}{c}\text { Average }=0.957 \\
C V=0.11\end{array}$ \\
\hline \multirow{10}{*}{ Kwak [12] } & FHB2-2 & \multirow{9}{*}{ Hooked } & 0.5 & 62.5 & 63.8 & 125 & 212 & 2.0 & 1.5 & 442 & 19 & & & & 134.89 & 117.09 & 1.152 \\
\hline & FHB 3-2 & & 0.75 & 62.5 & 68.6 & 125 & 212 & 2.0 & 1.5 & 442 & 19 & & & & 144.16 & 146.21 & 0.986 \\
\hline & FHB 2-3 & & 0.5 & 62.5 & 63.8 & 125 & 212 & 3.0 & 1.5 & 442 & 19 & & & & 81.89 & 81.56 & 1.004 \\
\hline & FHB $3-3$ & & 0.75 & 62.5 & 68.6 & 125 & 212 & 3.0 & 1.5 & 442 & 19 & & & & 90.1 & 97.41 & 0.925 \\
\hline & FHB 2-4 & & 0.5 & 62.5 & 63.8 & 125 & 212 & 4.0 & 1.5 & 442 & 19 & & & & 63.87 & 58.54 & 1.091 \\
\hline & FNB3-4 & & 0.75 & 62.5 & 68.6 & 125 & 212 & 4.0 & 1.5 & 442 & 19 & & & & 72.61 & 73.12 & 0.993 \\
\hline & FNB2-2 & & 0.5 & 62.5 & 30.8 & 125 & 212 & 2.0 & 1.5 & 442 & 19 & & & & 107.06 & 97.68 & 1.096 \\
\hline & FNB $2-3$ & & 0.5 & 62.5 & 30.8 & 125 & 212 & 3.0 & 1.5 & 442 & 19 & & & & 67.58 & 65.17 & 1.037 \\
\hline & FNB2-4 & & 0.5 & 62.5 & 30.8 & 125 & 212 & 4.0 & 1.5 & 442 & 19 & & & & 53 & 48.85 & 1.085 \\
\hline & & & & & & & & & & & & & & & & & $\begin{array}{c}\text { Average }=1.041 \\
C V=0.075\end{array}$ \\
\hline \multirow{10}{*}{$\begin{array}{l}\text { Greenough, } \\
\text { T. [16] }\end{array}$} & S-HE-50-0.5 & Hooked & 0.5 & 50 & 43.9 & 200 & 265 & 3 & 1.7 & 400 & 10 & & & & 90.85 & 99.74 & 0.911 \\
\hline & S-HE-50-0.75 & Hooked & 0.75 & 50 & 39.7 & 200 & 265 & 3 & 1.7 & 400 & 10 & & & & 105.6 & 118.77 & 0.889 \\
\hline & S-HE- $50-1.0$ & Hooked & 1.0 & 50 & 41.7 & 200 & 265 & 3 & 1.7 & 400 & 10 & & & & 148.9 & 141.87 & 1.050 \\
\hline & S-FE-50-0.5 & Hooked & 0.5 & 50 & 45.3 & 200 & 265 & 3 & 1.7 & 400 & 10 & & & & 115.5 & 100.63 & 1.148 \\
\hline & S-FE- $50-0.75$ & Flat end & 0.75 & 50 & 44.0 & 200 & 265 & 3 & 1.7 & 400 & 10 & & & & 144.1 & 121.59 & 1.185 \\
\hline & S-FE-50-1.0 & Flat end & 1.0 & 50 & 39.9 & 200 & 265 & 3 & 1.7 & 400 & 10 & & & & 146.8 & 140.68 & 1.044 \\
\hline & S-FE-30-0.5 & Flat end & 0.5 & 43 & 44.4 & 200 & 265 & 3 & 1.7 & 400 & 10 & & & & 106.7 & 93.96 & 1.136 \\
\hline & S-FE-30-0.75 & Flat end & 0.75 & 43 & 42.4 & 200 & 265 & 3 & 1.7 & 400 & 10 & & & & 122.9 & 111.41 & 1.103 \\
\hline & S-FE-30-1.0 & Flat end & 1.0 & 43 & 41.7 & 200 & 265 & 3 & 1.7 & 400 & 10 & & & & 151.4 & 129.68 & 1.167 \\
\hline & & & & & & & & & & & & & & & & & $\begin{array}{c}\text { Average }=1.070 \\
\mathrm{CV}=0.095\end{array}$ \\
\hline \multirow{7}{*}{ Ding Y [17] } & SFSCCB $25-\infty$ & \multirow{6}{*}{ Hooked } & 0.32 & 65 & 36 & 200 & 262 & 3 & 2.6 & 460 & 10 & & & & 105.26 & 81.38 & 1.293 \\
\hline & SFSCCB $50-\infty$ & & 0.64 & 65 & 41.7 & 200 & 262 & 3 & 2.6 & 460 & 10 & & & & 140.59 & 120.06 & 1.171 \\
\hline & SFSCCB $25-250$ & & 0.32 & 65 & 36 & 200 & 262 & 3 & 2.6 & 460 & 10 & 0.132 & 340 & 250 & 180.91 & 112.72 & 1.605 \\
\hline & SFSCCB $50-250$ & & 0.64 & 65 & 41.7 & 200 & 262 & 3 & 2.6 & 460 & 10 & 0.132 & 340 & 250 & 220.87 & 151.4 & 1.459 \\
\hline & SFSCCB $25-150$ & & 0.32 & 65 & 36 & 200 & 262 & 3 & 2.6 & 460 & 10 & 0.22 & 340 & 150 & 187.63 & 133.61 & 1.404 \\
\hline & SFSCCB $50-150$ & & 0.64 & $\begin{array}{l}05 \\
65 \\
\end{array}$ & $\begin{array}{r}30 \\
41.7 \\
\end{array}$ & 200 & $\begin{array}{l}202 \\
262\end{array}$ & 3 & $\begin{array}{l}2.0 \\
2.6\end{array}$ & $\begin{array}{l}400 \\
460\end{array}$ & 10 & 0.22 & $\begin{array}{l}540 \\
340\end{array}$ & 150 & 232.91 & $\begin{array}{l}153.01 \\
172.3\end{array}$ & $\begin{array}{l}1.404 \\
1.352\end{array}$ \\
\hline & & & & & & & & & & & & & & & & & $\begin{array}{c}\text { Average }=1.380 \\
\mathrm{CV}=0.098\end{array}$ \\
\hline
\end{tabular}

\section{CONCLUSIONS}

The following conclusions can be drawn from the experimental program on a series of steel fibre reinforced SCC beams with various parameters.

1. The equations to predict shear capacity, based on the concept of modified compression field theory, are proposed in which cracked fibre concrete is treated as a new material with its own stress-strain characteristics. A new equation of modified compression field theory for fibre reinforced concrete is proposed.

2. The addition of $60 \mathrm{~kg} / \mathrm{m}^{3}$ steel fibres was the upper bound of the fibre content regarding the workability of SCC members with a reinforcement ratio $3.35 \%$.

3. Steel fibres can enhance the shear cracking load and ultimate load of SCC beams. For fibre addition of $60 \mathrm{~kg} / \mathrm{m}^{3}$, the maximum shear capacity of SCC beams without stirrups was increased by up to $82 \%$ over that of beam without fibres. 
4. The diagonal shear as the cause for brittle failure in fibre reinforced SCC beams with different stirrup ratios $\left(\rho_{\mathrm{v}} \leq 0.413\right)$ changes to a mainly ductile flexural failure of fibre reinforced SCC beams when the fibre content achieves $60 \mathrm{~kg} / \mathrm{m}^{3}$.

5. The addition of $20 \mathrm{~kg} / \mathrm{m}^{3}$ fibres can partly replace the conventional stirrups and enlarge the stirrup spacing from $240 \mathrm{~mm}$ to $480 \mathrm{~mm}$, namely reducing the stirrup ratio about $0.137 \%$ in this study.

6. The combined use of stirrups and steel fibres shows great positive composite effect on shear load-carrying capacity, energy absorption capacity and toughness of SCC beams subjected to shear and bending.

7. The modified CSA equation for design to predict shear capacity was proposed. The accuracy of the proposed equation is validated using experimental data obtained on SFRC beams by the authors and other researchers. It is found to be simple and capable to provide reasonable estimates for the shear capacity of SFRC beams, and is thus suitable for implementation in design provisions after further validation.

\section{Acknowledgements}

The authors wish to acknowledge the National Natural Science Foundation of China (Grant: 51078058), Fundação para a Ciência e a Tecnologia (FCT) (SFRH/BPD/22680/2005), the Programa Operacional Factores de Competitividade COMPETE and FCT-within the Project PEst-C/MAT/UI0013/2011.

\section{NOTATION}

$\alpha$

$l_{f}$

$d_{f}$

$\rho_{s}$

$\rho_{v}$

a/d

$f_{\mathrm{c}}$ '

$d_{a}$

$f_{f}$

$\sigma_{f}$

$v_{f}$

SFRSCC

SF40-240

$b_{w}$

$d_{v}$
The aspect ratio

Fibre length

Equivalent diameter

The longitudinal reinforcement ratio

Stirrup ratios

Shear span-to-depth ratio

Cylinder compressive strength

Maximum aggregate size

Load of a single fibre transferred intersects at crack

Load component of a single fibre transferred perpendicular to crack

Load component of a single fibre transferred parallel to crack

Steel fibre-reinforced self-consolidating concrete

Steel fibre-reinforced self-consolidating concrete beams with $40 \mathrm{~kg} / \mathrm{m}^{3}$ steel fibre

content and a $240 \mathrm{~mm}$ spacing of stirrup

Width of the beam cross section

Effective depth of the beam cross section 


$\begin{array}{ll}h & \text { Depth of the beam cross section } \\ d_{m} & \text { The average of final diameter in slump flow test } \\ f_{y l} & \text { Yield stress of longitudinal reinforcement } \\ f_{y s t} & \text { Yield stress of stirrup } \\ T_{500} & \text { The time for concrete to reach the } 500 \mathrm{~mm} \text { spread circle in the slump test } \\ T_{200}, T_{400} & \text { Time taken for the mixture to reach } 200 \mathrm{~mm} \text { and } 400 \mathrm{~mm} \text { in the L-box test } \\ H_{2} / H_{1} & \text { The blocking ration in the L-box test } \\ F_{c r} & \text { Shear cracking load } \\ F_{u} & \text { The ultimate load }\end{array}$

\section{REFERENCE}

1. ACI Committee 544. State-of-the-art report on fiber reinforced concrete (ACI 544.IR-96). American Concrete Institute, Farmington Hills, Mich., 1997. p. 1-60.

2. Corinaldesi V, Moriconi G. Durable fiber reinforced self-compacting concrete. Cement and Concrete Research 2004; 34(2):249-254.

3. Sorelli L, Toutlemonde F. On the design of steel fibre reinforced concrete tunnel lining segments. In: 11th International conference on fracture; 2005.

4. Ding Y, You ZG, Jalali S. Hybrid fibre influence on strength and toughness of RC beams.Composite Structures 2010; 92(9): 2083-2089 .

5. Ding Y, et al. Experimental investigation on the mechanical of the fibre reinforced high-performance concrete tunnel segment. Composite Structures 2011; 93(4):1284-1289. 6. Ding Y, Kusterle W. Comparative study of steel fibre-reinforced concrete and steel mesh-reinforced concrete at early ages in panel tests. Cement and Concrete Research 1999; 29(11): 1827-1834.

7. Sharma AK. Shear strength of steel fiber reinforced concrete beams. ACI Journal 1983; 83(4):624-628.

8. Narayanan R, Darwish IYS. Use of steel fibres as shear reinforcement. ACI Structural Journal1987; 84(3): 216-227.

9. Ashour SA, Hasanain GS, Wafa FF. Shear Behaviour of high-strength fiber-reinforced concrete beams. ACI Structural Journal 1992; 89(2):176-184.

10. Adebar P, et al. Shear tests of fibre concrete beams without stirrups. ACI Structural Journal 1997; 94(1):68-76.

11. Lim DH, Oh BH. Experimental and theoretical investigation on the shear of steel fibre reinforced concrete beams. Engineering Structures 1999; 21(10):937-944.

12. Kwak Y, et al. Shear strength of steel fiber-reinforced concrete beams without stirrups. ACI Structural Journal 2002, 99(4): 530-538.

13. Cho S, Kim Y. Effects of steel fibers on short beams loaded in shear. ACI Structural Journal 2003; 100(6): 765-774.

14. Cucchiara C, La Mendola L, Papia M. Effectiveness of stirrups and steel fibres as shear reinforcement. Cement and Concrete Composites 2004; 26 (7): 777-786. 
15. Meda A, Minelli F, Plizzari G P, Riva P. Shear behaviour of steel fibre reinforced concrete beams. Materials and Structures 2005; 38(4):343-351.

16. Greenough T, Nehdi M. Shear behaviour of fiber-reinforced self-consolidating concrete slender beams. ACI Materials Journal 2008; 105(5): 468-477.

17. Ding Y, You Z, Jalali S. The composite effect of steel fibres and stirrups on the shear of beams using self-consolidating concrete. Engineering Structures 2011; 33(1):1107-117.

18. Minelli F, Vecchio J. Compression field modeling of fiber reinforced concrete members under shear loading. ACI Structural Journal 2006; 103(2): 244-252.

19. Joint ACI-ASCE Committee 445. Recent approaches to shear design of structural concrete. Journal of Structural Engineering, ASCE 1998; 124(12): 1375-1417.

20. Vecchio FJ, Collins MP. The modified compression field theory for reinforced concrete elements subjected to shear. ACI JOURNAL 1986; 83(2):219-231.

21. Collins MP, Mitchell D, Adebar P, Vecchio FJ. A general shear design method. ACI Structural Journal 1996; 93(1): 36-45.

22. Bentz EC, Vecchio FJ, Collins MP. Simplified modified compression field theory for calculating shear strength of reinforced concrete elements. ACI Structural Journal 2006; 103(4): 614-624.

23. Collins MP, Mitchell D. Prestressed Concrete Structures. Englewood Cliffs: Prentice Hall, 1991.

24. Stroeven P, Hu J. Effectiveness near boundaries of fibre reinforcement in concrete.

Materials and Structures 2006; 39: 1001-1013.

25. Stroeven P. Stereological principles of spatial modeling applied to steel fibre-reinforced concrete in tension. ACI Material Journal 2009; 106(3) 213-222.

26. CSA Committee A23.3. Design of Concrete Structures (CSA A23.3-04). Canadian

Standards Association, Mississauga, 2004.

27. Bentz EC, Collins MP. Development of the 2004 CSA A23.3 Shear Provisions for Reinforced Concrete. Canadian Journal of Civil Engineering 2006; 33(5): 521-534.

28. EFNARC. Specification and guidelines for self-compacting concrete; 2002.

29. The SCC European Project Group. The European Guidelines for Self-Compacting Concrete Specification. Production and use; 2005.

30. China standardization association of engineering construction standard CECS 13-2009.

Testing methods of steel fibre reinforced concrete; 2009.

31. National Standard of the People's Republic of China. Test methods of concrete structures (GB50152-92). Beijing: China Architecture \& Building Press, 1992 [in Chinese]. 